\title{
SHARE VALUATION AND CORPORATE EQUITY POLICY
}

\author{
Alan J. AUERBACH* \\ Harvard University and the National Bureau of Economic Research, Cambridge, MA 02138, USA
}

Received December 1977, revised version received December 1978

In recent years many contributions have appeared which examine the effects of corporate and personal taxation on firm financial policy. However, there has yet to appear an adequate explanation of why corporations continue to distribute dividends despite their disadvantageous tax treatment. We study this problem anew, in the context of an overlapping generations growth model with corporations financed by equity. Among our findings are: (1) capital owned by corporations may well be undervalued, even in the long run; (2) as a result of such undervaluation, firms may find it in the best interest of their stockholders to distribute dividends; and (3) an increase in the tax on distributions, while depressing the return to personal saving. may lead to an increase in the capital intensity of the economy. We also consider the criterion firms will use in evaluating new investment projects.

\section{Introduction}

In recent years, many contributions have appeared which examine the effects of corporate and personal taxation on firm financial policy. ${ }^{1}$ One important aspect of the problem in the U.S. and certain other countries is the preferential tax treatment accorded capital gains, which are taxed upon realization, and then only at a rate that is substantially below that on regular capital income. ${ }^{2}$ This provision has led Stiglitz (1973) and others to conclude that, in the absence of uncertainty, corporations should retain earnings as long as possible, with the eventual recovery of profits by shareholders taking the form of capital gains. Nevertheless, dividends remain an important method of transmitting corporate profits, and a framework capable of explaining such behavior is needed. The chief aim of this paper is to present and develop such a model.

*The author would like to thank Martin Feldstein, John Flemming, Jerry Green, and Lawrence Summers for discussions and helpful comments on previous drafts, and Anthony Atkinson for many useful suggestions, which include the ingenious diagram presented in this paper.

${ }^{1}$ See, for example, Gordon (1962), Farrar and Selwyn (1967), Pye (1972), Stapleton (1972), Stiglitz (1973, 1976) and King (1974).

${ }^{2}$ In the U.S., long-term capital gains are generally taxed at $50 \%$ of the rate on distributions, there existing various provisions which may make the rate higher or lower for particular taxpayers. 
An issue related to the firm financial decision is the proper criterion for new investment. Tobin (1969) has argued that firms will have an incentive to invest when the market price of their equity is greater than the reproduction cost of the capital which the equity represents.

In the present paper we explore once more the determinants of corporate equity policy and investment. Our economy consists of a large number of corporations which finance their capital investments solely through equity. These corporations behave in a perfectly competitive manner. Individuals save by purchasing shares of stock. The stock's value increases to reflect the retention of corporate earnings. We assume that all individuals have the same preferences and face the same marginal tax rates, and that, in addition to facing the same corporate tax rate, corporations face the same set of production possibilities.

Absent from the analysis is an important aspect of corporate finance, the issuance of debt. While, in reality, firms would generally find it advantageous to achieve a certain degree of leverage, there are various reasons, including legal restrictions and the possibility of bankruptcy, why firms would wish to maintain corporate equity at a certain level in their marginal financing. In the same vein, we have excluded the government and noncorporate sectors as alternative vehicles for personal saving.

There are a few remaining assumptions we desire to make which will rule out behavior that is either illegal or implausible. We assume that firms cannot buy back their own shares. It is evident that such a policy strictly dominates the issuance of dividends, since the sole difference between the two policies is the rate at which the personal receipts are taxed. However, share repurchases have historically been extremely small relative to regular dividend distributions in the U.S., ${ }^{3}$ perhaps, in part, because of Section 302 of the Internal Revenue Code which provides for the taxation at the regular personal tax rate of repurchases deemed to be in lieu of dividends. ${ }^{4}$ In the same spirit, we rule out any systematic interfirm share purchases using undistributed funds. Suppose, for the moment, that firms could pass through share earnings without additional corporate taxation. Then, by buying each other's shares, two firms could effectively circumvent the share repurchase prohibition. Actually, the U.S. tax code exempts only $85 \%$ of dividends received by corporations, and taxes capital gains at the corporate level. Thus, ignoring questions of legality, the superiority of interfirm shares purchases over dividends would depend on the average holding time of such shares. Regardless of the outcome of this calculation, it seems unrealistic to consider interfirm investment as more than a negligible use for corporate funds.

The partial taxation of firm-held shares could, in principle, be alleviated completely by outright acquisition of other firms. However, antitrust laws

\footnotetext{
${ }^{3}$ Relevant statistics are cited in Auerbach (1979).

${ }^{4}$ In the U.K., repurchases are prohibited outright.
} 
and other legal constraints pose barriers to such activity and, as in the case of simple investment in other firms' shares, it is not very plausible as a marginal alternative.

The above simplifications imply that firms may hold two types of assets: physical capital and liquid stocks which yield no physical return. If prices were subject to change or there were costs associated with shifts in production, there would be valid reasons for maintaining liquidity in the form of inventories. While we do not rule out such holdings in our model, we show in the Appendix that they will never be held by firms. Thus, all firm receipts, coming from profits and the sale of new shares, will either be distributed as dividends or retained and reinvested in new capital. Our results indicate that the superiority of capital gains over dividends as a method of profit distribution depends on the valuation of a share of stock. We find that, in a steady state, stock may be sufficiently undervalued so that dividends become an attractive method of distribution. With respect to the corporation's investment criterion, we concur that firms will finance investment through the sale of new shares only when share price exceeds reproduction cost. However, reinvestment of retained earnings will occur as long as share price exceeds a particular level which is strictly less than reproduction cost.

The share price which obtains in equilibrium varies in response to changes in the various rates of taxation. This has important implications for the return earned by investors, as well as the long-run capital intensity of the economy.

We present our model more explicitly in the following section. In section 3 we offer an analysis of how share prices may fall below reproduction cost in a dynamic economy. In section 4 we use comparative statics to analyze the effects that changes in different tax rates may have on the capital-labor ratio, return to investors, and share valuation, and illustrate these results diagrammatically with a Cobb-Douglas example. A few concluding comments appear in the final section.

\section{The model}

We examine the characteristics of a steady state in a one-sector nonmonetary growth model with overlapping generations of individuals. We assume there is no inflation, and take output as numeraire. This output may be used as capital or consumed, but, once it is put in place as capital it loses its fungibility and may not be consumed subsequently. Individuals live for two periods, and the population grows at rate $n$. At the end of each period, members of the younger generation save in the form of shares. There are no bequests, so that dividends received in the second period are consumed immediately, as are the receipts from the sale of all shares held. The value of 
a firm is the reproduction cost of the capital it holds, multiplied by Tobin's ' $q$ ', the ratio of share value to replacement cost. For simplicity, we always measure shares in units of capital, so that each share has price q. Thus, if firms increase their value by acquiring more capital, the number of shares outstanding, rather than the price per share, will increase. The process can be seen as a stock dividend in which new shares are given to each current stockholder in such a way as to maintain the amount of capital owned by each share. This should not be confused with the outside sale of new shares.

Labor supply per capita is taken to be fixed, and labor units are set so that each worker supplies one unit of labor.

An important issue is the use to which tax receipts are put. One can imagine several possibilities, including transfers to either or both generations, the purchase of public goods, or the investment in public projects. ${ }^{5}$ We assume for the sake of simplicity that tax receipts are spent by the government on items which do not affect individual decisions (e.g. military expenditures).

From the assumption of utility maximization, we may derive individual demand functions for first and second period consumption. Letting $r$ be the after-tax return to savers, second period consumption and saving are related by

$$
c_{2}=(1+r) s
$$

so that we may derive the savings function

$$
s=s(r, y)
$$

where $y$ is first period labor income.

Production in each firm is governed by the constant returns to scale relation

$$
x=f(k), \quad f^{\prime}>0 ; f^{\prime \prime}<0,
$$

where $k$ is the firm's capital-labor ratio. Since all firms are identical and follow the same policies, $k$ is also the economy-wide capital-labor ratio.

Savers buy shares, each representing one unit of capital, at price $q$. Thus, at any time the economy's capital stock is

$$
K_{t}=(s / q) N_{t}^{2}
$$

where $N_{t}^{2}$ is the population of the older generation at time $t$. Letting $N_{t}^{1}$ be

${ }^{5}$ Feldstein (1974) has demonstrated how the use to which government tax receipts are put may influence the long-run incidence of such taxes. 
the population of the younger generation, and hence the supply of labor to the economy, we know that $N_{t}^{1} / N_{t}^{2}=(1+n)$, so that

$$
k=s[q(1+n)]^{-1} .
$$

There are three taxes of concern in our analysis: the corporate tax rate, $\tau$, assessed immediately on all firm profits; the personal tax rate, $\theta$, on dividends; and the capital gains tax, $c$, applicable to gains realized on the sale of shares. ${ }^{6}$ We assume that all taxes are between zero and unity, and that $c$ is less than $\theta$. We also assume that wages are deductible from corporate profits for tax purposes; perfect competition ensures that firms will equate the marginal product of labor, gross of corporate taxes, with the wage rate. Thus, first period per capita income is

$$
y=f-k f^{\prime} .
$$

We turn now to the determination of firm equity policy. The firm's objective is to maximize the return of its current stockholders. If $q>1$, firms may sell new shares, purchase capital, and realize a gain of $(q-1)$ per share sold, which may then be distributed to current stockholders or reinvested. If $q<1$, firms would lose on each such sale. If $q=1$, firms are indifferent between selling and not selling new shares, since no gain or loss occurs. Thus, firms may be observed offering new shares only if $q \geqq 1$. Since firms would attempt to sell an infinite number of shares were $q>1$, it must also be true that $q \leqq 1$. Therefore, firms will offer new shares only if $q=1$, and there will never be a net gain or loss from such sales on the part of current stockholders. Thus, the net return per share, after corporate taxes, is simply the net marginal product of capital, $f^{\prime}(1-\tau)$. Since shares cost $q$, the rate of return on savings at the corporate level is

$$
\pi=f^{\prime}(1-\tau) / q \text {. }
$$

This return may be either retained and reinvested or distributed as a dividend. If the latter occurs, the return is taxed at rate $\theta$, so that the rate of return to savings is

$$
r_{\mathbf{D}}=f^{\prime}(1-\tau)(1-\theta) / q
$$

If the profits $\pi$ are reinvested, they may buy $f^{\prime}(1-\tau) / q$ units of capital, each having a share value of $q$. Thus, the increase in share value, or capital gain, 
resulting, would be $f^{\prime}(1-\tau)$. After capital gains taxation upon the sale of shares, this yields a return to savings of

$$
r_{\mathbf{R}}=f^{\prime}(1-\tau)(1-c) \text {. }
$$

From the fact that firms seek to maximize $r$, it follows that they will prefer dividends, retentions, or be indifferent, according to whether $q$ is less than, greater than, or equal to $q_{\mathrm{D}}$, where

$$
q_{\mathrm{D}}=(1-\theta) /(1-c)
$$

Since $q_{\mathrm{D}}<1$, firms in our model will never distribute dividends and issue new shares simultaneously. When $q$ is between $q_{\mathrm{D}}$ and unity, firms will not offer new shares to finance investment. However, they will reinvest all of their profits in new capital. Thus, the condition that $q$ be at least one is sufficient, but not necessary, for the existence of new investment. It is necessary only with respect to the offering of new shares.

To close our model we require that the stock market clear in every period. This means that shares of stock outstanding must grow at the same rate as the population, $n$. Additions to stock come from reinvestment of retained earnings and the sale of new shares. Thus, defining $\delta$ as the ratio of new issues to existing shares and $\gamma$ as the fraction of earnings distributed as dividends, the stock market equilibrium is described by the condition

$$
n=f^{\prime}(1-\tau)(1-\gamma)+\delta
$$

It follows from (11) that there will be dividends in equilibrium if and only if $f^{\prime}(1-\tau)>n$, and new share issues if and only if $f^{\prime}(1-\tau)<n$. It is also apparent that $q$ may never be less than $q_{\mathrm{D}}$ in a steady state. If it were, firms would offer no new shares and retain no earnings, i.e. $\delta=0$ and $\gamma=1$. Since $n$ is positive, this violates condition (11). The requirement that $q \geqq q_{\mathrm{D}}$ implies, in turn, that retentions will be at least as attractive as dividends, so that $r$ $=r_{\mathbf{R}}$. Using these restrictions, and the various equations of this section, we may now conveniently summarize the model we are using. The core of the model consists of four equations in six unknowns, $r, k, y, q, \delta$, and $\gamma$ :

$$
\begin{aligned}
k & =s(r, y)[q(1+n)]^{-1}, \\
r & =f^{\prime}(1-\tau)(1-c), \\
y & =f-k f^{\prime}, \\
n & =f^{\prime}(1-\tau)(1-y)+\delta .
\end{aligned}
$$

The remaining specification depends on the equity regime that applies. There 
are three regimes which are feasible, depending of the value of $q$. For each, there are additional conditions on $q, \delta$, and $\gamma$. The regimes, and their corresponding conditions, are presented in table 1 .

Table 1

Equity policy regimes.

\begin{tabular}{lll}
\hline Dividends & New shares & Conditions \\
\hline Yes & no & $\begin{array}{l}q=q_{\mathrm{D}} \\
\gamma>0 \\
\end{array}$ \\
& & $\delta=0$ \\
No & yes & $q=1$ \\
& & $\gamma=0$ \\
& & $\delta>0$ \\
No & no & $q \mathrm{D} \leqq q \leqq 1$ \\
& & $\gamma=0$ \\
& & $\delta=0$ \\
\hline
\end{tabular}

For each regime we have two additional equations in the unknowns $q, \delta$ and $\gamma$ which allow us to reduce the number of unknowns in (12) to four, plus an inequality constraint which must be satisfied by the resulting solution to (12). For example, for an equilibrium with dividends to occur, the value of $\gamma$ arrived at by solving (12) for $q=q_{\mathrm{D}}$ and $\delta=0$ must be non-negative.

Without characterizing the savings and production functions, we are unable to demonstrate the existence of a unique equilibrium in a particular regime for given values of $n, \tau, \theta$, and $c .^{7}$

\section{How can stock become undervalued?}

We have described above the steady-state behavior of an economy in which share prices may be below unity, so that ownership of capital may be valued at less than the reproduction cost of the capital itself. By what mechanism can this undervaluation come about?

The dynamics of adjustment for the general case would be extremely difficult to model. However, insight into the problemı may be gained by examining the simple case in which per capita savings is fixed.

Consider an economy 'just starting up' in which individuals of the first generation buy $s$ units of capital each. At the end of the next period the stockholders not only have the original $s$ units of capital to sell, but also have profits of $s f^{\prime}(1-\tau)$. As long as price per share remains at one, the return will be greater from reinvesting these profits in new capital, rather

\footnotetext{
${ }^{7}$ Theoretically, it might be possible for multiple equilibria to exist within a particular regime, or for equilibria to exist in more than one regime. For the Cobb-Douglas example presented below, there exists a unique equilibrium for each set of tax values.
} 
than taking dividends. Suppose all of the profits are reinvested. Then the stock of capital must grow by a factor of $f^{\prime}(1-\tau)$, while the demand for capital by the next generation is $(1+n)$ times that of the current owners. If $n$ exceeds $f^{\prime}(1-\tau)$, all share sales will be accommodated and new shares will be issued to satisfy any remaining demand. But if $n<f^{\prime}(1-\tau)$, not all shares can be sold. The excess supply of shares will drive down their price. As long as the price remains above $(1-\theta) /(1-c)$, it will still be advantageous to the older generation to reinvest and absorb the lower value of the stock than distribute dividends. If $q$ falls to $q_{\mathrm{D}}$, current stock owners will be indifferent between retentions and dividends. The price can fall no more, since this would eliminate all reinvestment and, as long as $n$ is positive, there would be an excess demand for shares.

If $q<1$, then the new generation is able to buy more than one dollar of capital per dollar of savings. Thus, the capital-labor ratio in the following period will be higher, and $f^{\prime}$ will be lower. If $f^{\prime}(1-\tau)$ declines to $n$, then all profits can be reinvested and shares can be sold to the third generation at the price that cleared the market in the previous period, since shares and savings will have grown at the same rate. If $f^{\prime}(1-\tau)$ remains above $n$, full reinvestment will lead to an excess supply of shares at that price, and $q$ must fall again. If the new market-clearing price is above $(1-\theta) /(1-c)$, this policy remains superior to dividend payouts. However, if the price reaches $q_{\mathrm{D}}$, firms will choose to reinvest only a portion of their earnings, and offer dividends.

This process would continue over time. Eventually, one of two outcomes would have to occur. If $q$ declines to $(1-\theta) /(1-c)$ before $f^{\prime}(1-\tau)$ declines to $n$, then dividends will be paid and $\left[f^{\prime}(1-\tau)-n\right]$ will remain positive. If $f^{\prime}(1$ $-\tau)$ reaches $n$ and $q$ exceeds $(1-\theta) /(1-c)$, then $q$ will stop falling and there will be no dividends paid in equilibrium.

\section{Effects of tax rate changes}

We now examine the general equilibrium effects that changes in the tax rates $\tau, c$, and $\theta$ have on the steady-state values of $k$, the capital-labor ratio, $r$, the return to savings, and $q$, the share price of a unit of firm-held capital, for each of the three regimes discussed above. The results are listed in table 2. For ease of exposition, we totally differentiate each system with respect to $\tilde{\tau}=(1-\tau), \tilde{\theta}=(1-\theta)$, and $\tilde{c}=(1-c)$, rather than the taxes themselves. Note that the elasticity of any parameter $i$ with respect to any $\operatorname{tax} j, \eta_{i j}$, has the opposite sign from the elasticity of $i$ with respect to $j$. Therefore, we present the values of $-\eta_{i j}$ in the table.

Many of the results depend on the values of $\eta_{s r},\left[1-\left(S_{K} / \sigma\right) \eta_{s y}\right]$ and $\Delta$ (defined in table 2). The first is the uncompensated or 'total' supply elasticity of personal savings with respect to the rate of return. In theory, $\eta_{s r}$ may be positive or negative. Econometric research has traditionally found $\eta_{s r}$ to be 
Table 2

Tax change effects."

\section{Regime}

Retained earnings

+ new shares

Retained earnings only

$-\frac{\sigma}{S_{L}}$

0
Retained earnings +dividends

$-\frac{1}{4} \eta_{s r}$

$-\frac{1}{\Delta}\left(1-\frac{S_{K^{\prime}}}{\sigma} \eta_{s y}\right)$

$-\frac{1}{\Delta}\left(1-\frac{s_{k}}{\sigma} \eta_{s y}\right)$

0

$\frac{\sigma}{S_{L}}\left(1-\frac{S_{K}}{\sigma} \eta_{s y}\right)$

0

$-\frac{1}{\Delta} \eta_{s r}$

0

$-\frac{1}{\Delta}\left(1-\frac{S_{K}}{\sigma} \eta_{s y}\right)$

$-1$

$-\eta_{s r}$

0

0

0

0
$-\frac{1}{\Delta}\left(\eta_{\mathrm{sr}}+1\right)$

$-\frac{1}{\Delta}\left(1-\frac{S_{K}}{\sigma} \eta_{s y}-\frac{S_{L}}{\sigma}\right)$

1

$\frac{1}{\Delta}$

$-\frac{1}{\Delta} \frac{S_{L}}{\sigma}$ $-1$

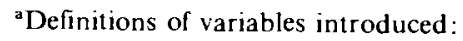

$\eta_{i j}=$ elasticity of $i$ with respect to $j$,

$S_{L}=$ labor share of output; $=\left(f-k f^{\prime}\right) / f$,

$S_{K}=$ capital share of output $;=k f^{\prime} / f$,

$\sigma=$ elasticity of substitution; $=\mathrm{d} \ln k / \mathrm{d} \ln \left(\frac{f-k f^{\prime}}{f^{\prime}}\right)$,

$\Delta=1+\frac{1}{\sigma}\left(\eta_{s r} S_{L}-\eta_{s y} S_{K}\right)$

imall and of uncertain sign. However, Feldstein (1970) has suggested that, oecause they failed to use the real interest rate, such estimates may have been biased toward zero. After compensating for this and other possible problems, Boskin (1978) has estimated $\eta_{s r}$ to be much larger than previously anticipated, with a value of about 0.4 . 
As long as neither first nor second period consumption is an inferior good, $\eta_{s y}$ is positive. In an economy like the U.S., in which savings is roughly a fixed fraction of income, $\eta_{s y}$ should be approximately unity. Since $S_{K}$, the capital share of output, is about $0.3,\left[1-\left(\mathrm{S}_{K} / \sigma\right) \eta_{s y}\right]$ will be positive unless $\sigma$ $<0.3$, which is implausible. ${ }^{8}$

For the remainder of the analysis we assume that $\eta_{s r}$ and $\left[1-\left(S_{K} / \sigma\right) \eta_{s y}\right]$ are positive, as seems likely. These assumptions are sufficient, though not necessary, to guarantee that $\Delta$ will also be positive.

\subsection{Retained earnings and dividends}

This is the regime most relevant to current conditions in the U.S., since dividends are paid out, new share issues are small, and the rate of after-tax corporate profits exceeds the growth rate. ${ }^{9}$ Total differentiation of (12) for $q$ $=q_{\mathrm{D}}$ and $\delta=0$ yields the results in the last column of table 2 .

Of particular interest are the differences in impact of the three taxes on $k$ and $r$. The effects of an increase in the corporate tax rate, $\tau$, correspond most closely to those found in earlier work. ${ }^{10}$ As long as savings is interest elastic, the lower rate of return induced by the tax leads to a lower steady-state capital stock. This raises the marginal product of capital, so that the net rate of return, $r$, falls by less than the full tax increase. The fraction of the tax increase which is shifted in this way depends negatively on the degree to which labor may be substituted for capital in production, as represented by the elasticity of substitution, $\sigma$.

Since $q$ equals $q_{\mathrm{D}}$ in equilibrium, an increase in $\tau$ has no effect on $q$. Because $q_{\mathrm{D}}$ is determined by $\theta$ and $c$, an increase in either of these tax rates will have a more complicated effect than $\tau$ on $k$ and $r$, since $q$ must also change. (It is easily verified that a simultaneous change in $\theta$ and $c$ which leaves $q_{\mathrm{D}}$ unchanged is identical in effect to an increase in $\tau$.) For a given value of $q$, an increase in $\theta$ makes dividends less attractive than retentions, and would lead to greater capital accumulation. For equilibrium to be reestablished, $q$ must fall to the new, lower value of $q_{\mathrm{D}}$, at which firms would once again be willing to distribute dividends. On the other hand, an increase in $c$ would encourage payout of all profits unless $q$ rose. While we are not attempting to model the transition from one steady state to another, one's intuition might suggest that an increase in $\theta$ would depress capital accumu-

\footnotetext{
${ }^{8}$ Nerlove (1967) presents an excellent survey of attempts at estimating $\sigma$. Time series estimates for aggregate U.S. production generally fall between 0.5 and 0.7 . However, cross-section estimates of $\sigma$ for two-digit SIC industries tend to be much higher than the corresponding time series estimates, suggesting that the aggregate estimates may be too low.

${ }^{9}$ The maximum value of $\tau$ in the U.S. is presently 0.46 Feldstein and Summers (1977) have estimated the marginal product of corporate capital to be about $11 \%$. The economy's trend growth rate, taking account of technical change, is lower than the implied value of $f^{\prime}(1-\tau)$, $5.94 \%$.

${ }^{10}$ See Feldstein (1974), for example.
} 
lation less than an equivalent increase in $c$, because of these different effects on $q_{\mathrm{D}}$. In fact, an increase in $\theta$ actually leads to an increase in the capitallabor ratio, while $k$ is depressed (and $f^{\prime}$ increased) so much by an increase in $c$ that, for $\eta_{s y}=1, r$ increases when $\sigma<1$.

The results for this regime indicate that, once equity policy and valuation are accounted for, the effects of an increase in capital income taxation depend on the type of tax change. While a corporate tax increase depresses both the capital-labor ratio and the rate of return, increasing the rate of personal taxation, $\theta$, increases $k$, while an increase in $c$, the capital gains tax rate, may depress $k$ so much that $r$ increases.

\subsection{Retained earnings and new shares}

This regime, which occurs if $f^{\prime}(1-\tau)<n$, is simpler to describe than the one above, since $q$ is fixed at unity. An increase in $\tau$ has the same impact as before. Because $q$ is not a function of $c$, and since all earnings are retained and thus taxed at the capital gains rate, an increase in $c$ is equivalent to an increase in $\tau$. Similarly, since there are no dividends at the margin, a change in $\theta$, the rate of dividend taxation, has no effect at all.

\subsection{Retained earnings only}

The intermediate case between those already discussed is that in which $q$ is between $q_{\mathrm{D}}$ and one, so that all earnings are retained, but no new shares are issued. Because dividends are not paid, $\theta$ once again has no effect on the equilibrium values of $k$ and $r$. Since $q$ is endogenous, the results of changing $\tau$ or $c$ are unlike those found in either of the above regimes.

The key to the results lies in the fact that $f^{\prime}(1-\tau)=n$. Thus, an increase in $c$ can have no effect on the equilibrium value of $k$, so that it will be fully reflected by a drop in $r$. Since this leads to less saving, $q$ must drop to maintain equality between the capital supplied and demanded in equilibrium. On the other hand, an increase in $\tau$ can have no effect on $f^{\prime}(1-\tau)$, and hence $r$, so that $f^{\prime}$ must increase, and $k$ decline, accompanied by an increase in $q$. Thus, an increase in $c$ is fully reflected in the net rate of return, while an increase in $\tau$ is, eventually, completely shifted.

\subsection{An example}

One case in which there is a unique equilibrium for each set of tax rates, and which may be illustrated diagrammatically, is that in which both production and utility may be represented by Cobb-Douglas functions. The production function is written

$$
x=f(k)=a k^{\beta}, \quad 0<\beta<1 .
$$


The utility function is

$$
U=c_{1}^{\alpha} c_{2}^{(1-\alpha)}, \quad 0<\alpha<1 .
$$

Utility maximization leads to the savings function

$$
s=(1-\alpha) y
$$

Combining (12.1) and (12.3), and using (13) and (15), we obtain

$$
q=m f^{\prime}(k)
$$

where $m$ is a constant, not dependent on tax rates. This condition relates $q$ to $k$, and must hold regardless of regime. It is represented by the line labelled $q(k)$ in fig. 1. It follows immediately that the equilibrium value of $k$ must lie between the values labeled $k_{1}$ and $k_{2}$, since $q$ is between $q_{\mathrm{D}}$ and one. To solve for equilibrium, we rewrite eq. (12.4) as

$$
(n-\delta) /(1-\gamma)=f^{\prime}(k)(1-\tau),
$$

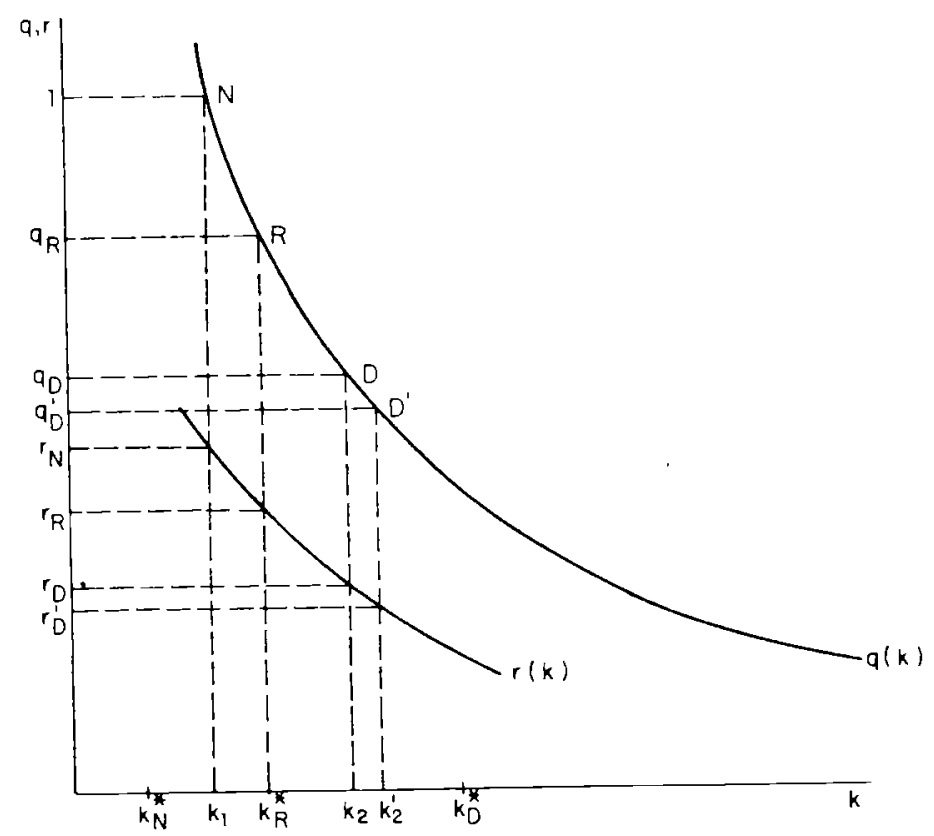

Fig. 1 
Ind let $k^{*}$ be the value of $k$ obtained by solving (17) for $\delta=\gamma=0$. Since $f^{\prime \prime}$ $<0$, if $k<k^{*}$ then $\gamma>0$. Similarly, if $k>k^{*}, \delta>0$. The actual value of $k$ in quilibrium depends on the relation of $k^{*}$ to $k_{1}$ and $k_{2}$. Since $k$ must be reater than or equal to $k_{1}$, if $k^{*}<k_{1}$, then $k^{*}<k$ and $\delta>0$. But then we now that $q=1$, and hence $k$ must equal $k_{1}$. Similarly, if $k^{*}$ exceeds $k_{2}$, then $*^{*}>k$ and $\gamma>0$, so that $q=q_{\mathrm{D}}$ and $k=k_{2}$. Finally, if $k^{*}$ lies between $k_{1}$ and 2 , the only possible regime is that with $\delta=\gamma=0$, so that $k=k^{*}$ and $q$ $=q\left(k^{*}\right)$. These three possibilities are represented in the diagram by the values N,$k_{\mathrm{D}}^{*}$, and $k_{\mathrm{R}}^{*}$, respectively, with corresponding points on $q(k)$ labeled $N, D$, nd $R$. Equilibrium values of $r$ may be read from the $r(k)$ curve, which epresents eq. (12.2).

The effects of tax changes may easily be seen using this diagram. For xample, an increase in $\theta$ lowers $q_{\mathrm{D}}$ to $q_{\mathrm{D}}^{\prime}$, which shifts $k_{2}$ to $k_{2}^{\prime}$. This has no ffect unless there are dividends being paid, in which case $k$ increases to $k_{2}^{\prime}$ nd $r$ drops to $r_{\mathrm{D}}^{\prime}$. A decrease in $c$ would also lower $q_{\mathrm{D}}$, but would cause an pward shift in the $r(k)$ curve, leading to increases in $r_{N}$ and $r_{\mathbf{R}}$ and, in this pecial Cobb-Douglas case, keeping $r_{D}$ constant. A decrease in $\tau$ would also aise $r(k)$, would have no effect on $q_{\mathrm{D}}$, but would raise $k^{*}$ [see (17)]. This rould increase $k$ and lower $q$ for the intermediate regime, raising the rate of eturn under each of the other regimes.

\section{Conclusions}

We have, in this paper, used a simple dynamic model to study the effects t taxes on corporate equity policy. Among our findings are the following.

(1) Capital owned by corporations may well be undervalued, even in the ng run.

(2) As a result of such undervaluation, firms may find it in the best terest of their stockholders to distribute dividends.

(3) Firms will finance investment with the sale of new shares only if share rice exceeds reproduction cost; on the other hand, retained earnings will be invested as long as share price exceeds a value strictly less than reprouction cost.

(4) While tax increases are likely to depress the return to personal saving, increase in the tax on distributions may lead to an increase in the conomy's capital intensity by encouraging the reinvestment of corporate ofits.

Much work remains to be done on this subject. A more realistic study of e present problem would incorporate alternative assets, such as bonds and on-corporate capital. Another extension would take into account the ogressivity of the actual structure, and the existence of investors with fferent marginal tax rates. ${ }^{11}$

${ }^{11}$ I have explored some of these issues in later work. See Auerbach (1979). 
As stated in the opening section, there are effects other than tho considered in this essay which determine corporate equity policy, particular dividend behavior. Nevertheless, we believe our results to be an importar contribution to the understanding of this difficult question.

\section{Appendix}

We demonstrate here that, in our model, it will never be advantageous $f c$ firms to invest in liquidity rather than capital.

Since the market values capital at $q$, shareholders will gain from a fir investment in liquid stocks only if the valuation of such stocks is greater pe unit than $q$. Let this value be denoted $q_{L}$. Now consider the return a investor can get on that part of a share which represents liquid stocks. If th liquidity is taken as a dividend, the investor receives one dollar for every dollars invested, which is taxed at rate $\theta$, yielding a return of

$$
r_{\mathbf{D}}^{L}=\frac{1-\theta}{q_{L}}-1
$$

Since $q_{L} \geqq q \geqq(1-\theta) /(1-c)>(1-\theta), r_{\mathrm{D}}^{L}$ is negative.

If the stocks are invested in capital, the capital will have less value, since $<q_{L}$. Thus, the return upon sale will be negative. Finally, if the stocks at held for one period, they maintain their value, yielding a return of zero. Sinc $r_{\mathrm{R}}=f^{\prime}(1-\tau)(1-c)>0$, firms will never hold any liquid stocks.

\section{References}

Auerbach, A.J., 1979, Wealth maximization and the cost of capital, Quarterly Journal Economics 93, forthcoming.

Boskin, M.J., 1978, Taxation, saving and the rate of interest, Journal of Political Economy S3-S27.

Diamond, P.A., 1965, Debt in a neoclassical growth model, American Economic Review 1126-1150.

Diamond, P.A., 1970, Incidence of an interest income tax, Journal of Economic Theory 2, 21 224.

Farrar, D.F. and.L.L. Selwyn, 1967, Taxes, corporate financial policy and return to investo National Tax Journal 20, 444-454.

Feldstein, M.S., 1970, Inflation, specification bias and the impact on interest rates, Journal Political Economy 78, 1325-1339.

Feldstein, M.S., 1974, Incidence of a capital income tax in a growing economy with variat savings rates, Review of Economic Studies 41, 505-513.

Feldstein, M.S. and L. Summers, 1977, Is the rate of profit falling?, Brookings Papers Economic Activity, 211-228.

Feldstein, M.S., J. Green and E. Sheshinski, 1979, Corporate financial policy and taxation in growing economy, Quarterly Journal of Economics 93, forthcoming.

Flemming, J.S., 1976, A reappraisal of the corporation income tax, Journal of Public Economi 6, 163-169.

Gordon, M.J., 1962, The investment financing and valuation of the corporation (Irwi Homewood, Ill.). 
King, M.A., 1974, Taxation and the cost of capital, Review of Economic Studies 41, 21-35.

Modigliani, F. and M.H. Miller, 1958, The cost of capital, corporation finance and the theory of investment, American Economic Review 48, 261-297.

Nerlove, M., 1967, Recent empirical studies of the CES and related production functions, in: M. Brown, ed., The theory and empirical analysis of production (NBER, New York).

Pye, G., 1972, Preferential tax treatment of capital gains, optimal dividend policy, and capital budgeting, Quarterly Journal of Economics 86, 226-242.

Stapleton, R.C., 1972, Taxes, the cost of capital and the theory of investment, Economic Journal 82, 1273-1292.

Stiglitz, J.E., 1973, Taxation, corporate financial policy, and the cost of capital, Journal of Public Economics 2, 1-34.

Stiglitz, J.E., 1976, The corporation tax, Journal of Public Economics 5, 303-311.

Tobin, J., 1969, A general equilibrium approach to monetary theory, Journal of Money, Credit and Banking 1, 15-29. 